\title{
Multi-Objective, Multi-Period Optimization of Biomass Conversion Technologies Using Evolutionary Algorithms and Mixed Integer Linear Programming (MILP)
}

\author{
Samira Fazlollahi ${ }^{\mathrm{a}, \mathrm{b}, *}$, Francois Maréchal ${ }^{\mathrm{b}}$ \\ ${ }^{a}$ Veolia Environnement Recherche et Innovation (VERI), 291 avenue Dreyfous Ducas, \\ 78520 Limay, France \\ ${ }^{b}$ Ecole Polytechnique Federale de Lausanne, LENI-IGM-STI-EPFL Station 9- 1015 \\ Lausanne, Switzerland
}

\begin{abstract}
The design and operation of energy systems are key issues for matching energy supply and demand. A systematic procedure, including process design and energy integration techniques for sizing and operation optimization of poly-generation technologies is presented in this paper. The integration of biomass resources as well as a simultaneous multi-objective and multi-period optimization, are the novelty of this work. Considering all these concepts in an optimization model makes it difficult to solve. The decomposition approach is used to deal with this complexity.

Several options for integrating biomass in the energy system, namely back pressure steam turbines, biomass rankine cycles (BRC), biomass integrated gasification gas engines (BIGGE), biomass integrated gasification gas turbines, production of synthetic natural gas (SNG) and biomass integrated gasification combined cycles (BIGCC), are considered in this paper. The goal is to simultaneously minimize costs and $\mathrm{CO}_{2}$ emission using multi-objective evolutionary algorithms (EMOO) and Mixed Integer Linear Programming (MILP).

Finally the proposed model is demonstrated by means of a case study. The results show that the simultaneous production of electricity and heat with biomass and natural gas are reliable upon the established assumptions. Fur-
\end{abstract}

\footnotetext{
${ }^{*}$ Corresponding author

Email addresses: samira.fazlollahi@epfl.ch, (Samira Fazlollahi), francois.marechal@epfl.ch (Francois Maréchal )
} 
thermore, higher primary energy savings and $\mathrm{CO}_{2}$ emission reduction, $40 \%$, are obtained through the gradual increase of renewable energy sources as opposed to natural gas usage. However, higher economic profitability, $52 \%$, is achieved with natural gas-based technologies.

Keywords:

Poly-generation systems, Mixed Integer Linear Programming, Evolutionary algorithm, Biomass conversion technologies, $\mathrm{CO}_{2}$ mitigation

\section{Introduction}

In the perspective of increasing the share of renewable energies to mitigate global warming and with respect to the global issue of sustainable energy development, biomass has been increasingly focused on as a potential source of renewable energy. Poly-generation technologies, joined with the integration of biomass, have a good potential for $\mathrm{CO}_{2}$ emissions reduction. Table.1 compares the lifecycle $\mathrm{CO}_{2}$ emissions of biomass with other resources and shows the potential of biomass for $\mathrm{CO}_{2}$ emissions reduction. This data is selected from the ecoinvent life cycle inventories database [1]. $\triangle \mathrm{CO}_{2}$ in Table.1 shows the $\mathrm{CO}_{2}$ emissions of resources minus the $\mathrm{CO}_{2}$ emissions of biomass. The biogenic carbon captured by photosynthesis is not accounted for the biomass $\mathrm{CO}_{2}$ emissions. In addition, if any $\mathrm{CO}_{2}$ mitigation technology is adopted [2], negative $\mathrm{CO}_{2}$ emissions will be realized, which can reduce the emissions in the atmosphere [3].

In the present work, several options for integrating biomass in a poly-

Table 1: $\mathrm{CO}_{2}$ Intensity of resources

\begin{tabular}{lcc}
\hline Resources & $\begin{array}{c}\mathrm{CO}_{2}-\mathrm{Eq}:[1] \\
{[\mathrm{kg} / \mathrm{MJ}]}\end{array}$ & $\begin{array}{c}\triangle \mathrm{CO}_{2} \\
{[\mathrm{~kg} / \mathrm{MJ}]:}\end{array}$ \\
\hline Electricity & 0.3155 & 0.3071 \\
Natural Gas & 0.0725 & 0.0641 \\
Biomass & 0.0084 & 0 \\
\hline
\end{tabular}

generation plant are studied, however before going forwards, a systematic optimization procedure is needed to select and size the equipments. The optimization of energy systems that include one or more technologies to meet the requirements of energy systems is extensively studied by many authors. It is referred to [4] for a detailed overview. From the author's point of view, the 
majority of studies can be divided into two main categories; the first category includes thermo-economic simulations and synthesis of biomass technologies and the second category includes optimization techniques for selecting and sizing equipments.

Researchers have paid much attention in the literature on thermo-economic simulations and synthesis of biomass technologies in cogeneration plants. A trigeneration system using a heat engine and a vapour compression chiller, running on biofuel, is simulated in [5] and a comparative analysis between the biofuel trigeneration and conventional fossil fuel was carried out. The energy and the exergy efficiencies of trigeneration system consisting of a biomass combustor, an ORC, a single-effect absorption chiller, and a heat exchanger are studied in [6] through a simulation. Process integration methodology and simulation is applied in [7] to deal with an application of a heat pump in energy systems for biomass gasification in a wood processing plant. For a detailed overview, simulation and modelling of biomass based cogeneration systems are reviewed in [8]. Most of these publications carried out only simulations, while system design optimization is neglected.

The second state of the art part of this work is on optimization techniques for selecting and sizing equipments. Diverse procedures exist to size cogeneration plants, like a structural optimization approach based on the mixed-integer linear programming [9]. Lyer and Grossmann [10] conducted a work on utility systems optimization for a multi-period operating condition by using a MILP method, however it was limited to the steam network model. Other researchers [11] developed a mono objective optimization model for the integration of cooling and heating systems based on the process integration and temperature intervals. A mono objective operations optimization and the design of tri-generation plants is also studied in [12]. Some limitations related to the simultaneous consideration of the economic evaluation and the $\mathrm{CO}_{2}$ emissions assessment may appear in available optimization methods developed in [13] and [14]. Moreover, a mathematical programing model for selection and sizing of alternative equipments in a poly-generation scheme was investigated by researchers [15]. Three algorithms based on evolutionary and/or social metaphors for mono objective energy systems optimization problems were studied in [16]. An optimization tool for a district energy system design is presented in [17]. For a detailed overview, the role of optimization modelling techniques in power generation is reviewed in [18]. However, most of these optimization models only included a mono economic objective function, completed with environmental and energetic targets as constraints, rather than 
multi objective optimization, as is done here.

To sum up, energy system analyses are extensively studied by many authors. However, a systematic procedure including process design and energy integration techniques with simultaneous consideration of multi-periods and multi-objective aspects for energy system designs is still missing. Considering all these concepts in a single optimization model defines a Mixed Integer non-Linear Problem (MINLP) with non differentiable equations due to the use of the temperature as decision variable in heat cascade constraints.

The purpose of the developed model in this paper is to use the decomposition approach to deal with this complexity. In order to do so, a multi-objective optimization model with evolutionary algorithms (EMOO) and MILP has been developed (sec.2)

In the developed model the features of both above mentioned types of study; the integration of biomass technologies' simulation models in the energy system as well as multi objective optimization for sizing a cogeneration plant, are combined in a systematic procedure. This procedure evaluates the total costs and the $\mathrm{CO}_{2}$ emissions simultaneously by decomposing the model into master and slave optimizations [19]. The considerations of several equipments as well as their thermodynamic properties (sec.3), including process design and energy integration techniques with simultaneous consideration of multi-periods and multi-objective aspects (sec.2.3), are important advantages in the present work. Finally, the developed model is demonstrated by means of a case study (sec.4). Results are compared to conclude advantages and disadvantages of alternative solutions (sec.4.1).

The energy system analyses could be divided into two major steps; first sizing and design optimization and second, operation optimization. The developed model in this paper is mainly used for the conceptual design and sizing optimization. The system configuration is optimized in this step. After that, the operation optimization will be done with more detailed modeling including a storage system, part load efficiency and advance control system by fixing the system configuration as an input data. Never the less this detail operation optimization is only possible if a feasible solution for a system configuration is obtained in the first step. 


\section{Methodology overview}

In energy systems, conversion technologies are used to transform the primary energy into useful services. Several technologies may be used simultaneously or in competition. The goal is to provide the energy requirements at the minimum costs.

In this work, multi-objective optimization techniques are exploited in order to investigate sizing and operating effects of a poly-generation technology on $\mathrm{CO}_{2}$ emissions. The basic concept of the developed model is the decomposition of the problem into several parts, as illustrated in Fig.1.

The developed model is a mixed integer non-linear problem (MINLP). It is

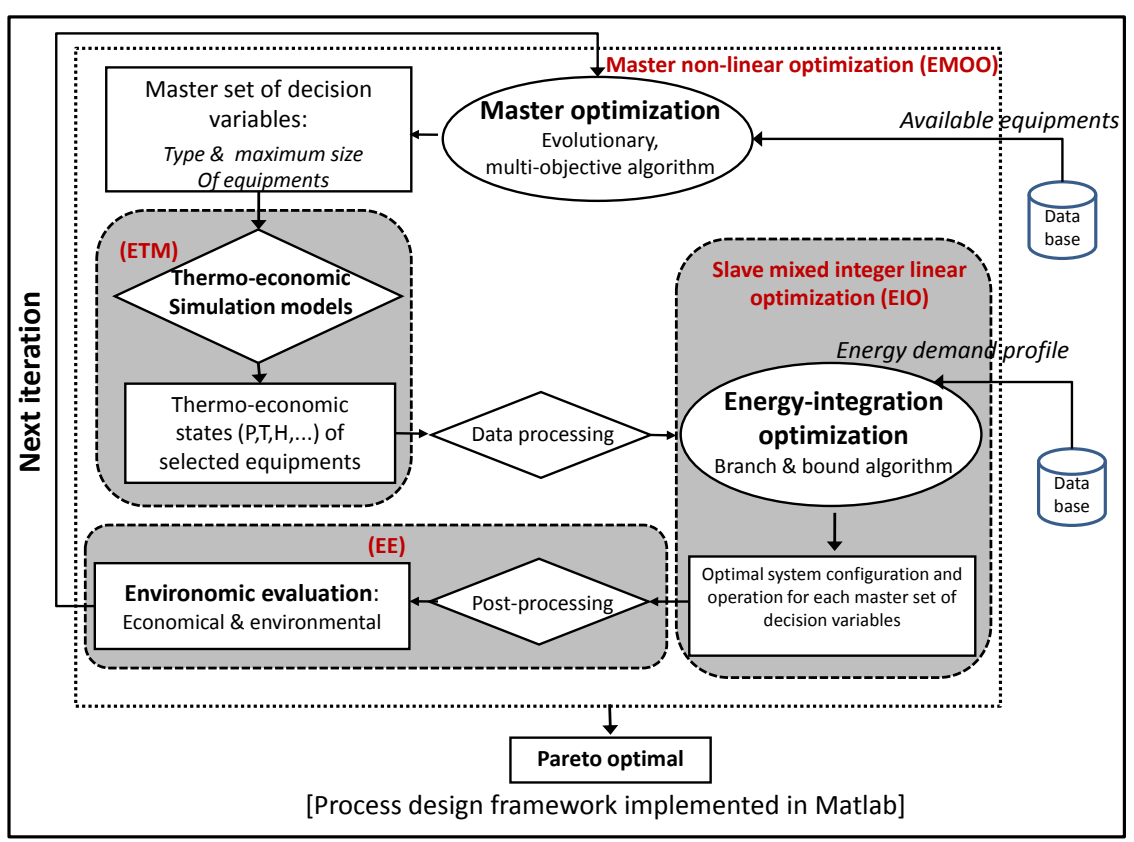

Figure 1: Overall decomposition optimization sequence

solved by a decomposition method using a master slave algorithm in which decision variables are partitioned into two groups, master and slave sets [20]. The master set of decision variables include the type and the maximum available size of equipments. These variables are used to define possible superstructures for a district energy system. A list of available and alternative equipments is the main input data for the master optimization. 
The master optimization including the first group of variables is solved by an evolutionary algorithm (EMOO) (sec.2.1).

The district system's superstructure is initialized based on the values of the master decision variables.

Subsequently, in the second step the thermodynamic and economic state of the selected superstructure is calculated by using thermo-economic simulation models (sec.2.2). This is an intermediate step between the master and the slave optimization, named ETM. Here, the goal is to calculate the cost, the heat transfer, the temperature, the enthalpy and the power requirements of selected equipments. These values, the list of available energy sources and the energy consumption profiles (including the temperature and power levels) are the main input data for the slave optimization.

The next step is the slave optimization, an energy integration problem (EIO) formulated as a mixed integer linear model (MILP) (sec.2.3). It will calculate the best usage of equipments in the selected superstructure in order to supply the requirements of the system. It is solved by robust linear programming methods. Here the aim is to minimize the total cost under the heat and power cascade constraints.

The selected superstructure in the master level and the result of the slave optimization are used in the post processing phase to calculate objective functions of the master optimization. In most cases these objective functions are environomic (environment, economics and thermodynamics) indicators. This step is called the environomic evaluation (EE).

These steps; the selection of master decision variables (EMOO); thermoeconomic simulations (ETM); slave optimization (EIO) and environomic evaluations (EE), are repeated during several iterations. The user should define the number of iterations before running the master optimisation.

After all iterations are completed the results will be presented by the Pareto optimal frontier.

The main decision variables in the slave and the master optimization are summed up in Table.2.

The communication between the software used for the different modeling and optimization steps has been realized by developing a computational platform programmed in Matlab language [21].

2.1. Master optimization: the evolutionary, multi-objective optimization (EMOO)

Multi-objective optimization techniques have been exploited in the conceptual design of energy systems to generate an enlarged set of candidate 
Table 2: Decision variables in the slave and the master optimization

\begin{tabular}{ll}
\hline Optimization/ Simulation steps & Variables \\
\hline Master Optimization: & Type of the district energy conversion \\
(Evolutionary algorithm (EMOO)) & technologies (systems superstructure), \\
& Maximum size of the district energy \\
& conversion technologies \\
Thermo-economic simulation models: & The corresponding thermodynamic states \\
(ETM) & (the temperature, the enthalpy, the power) \\
& the investment turnkey cost of conversion \\
& technologies \\
Slave optimizer: & Utilization rate and the operation \\
(MILP) & strategy of district conversion technologies \\
\hline
\end{tabular}

solutions. These techniques are used for a design problem that is characterized by several conflictive objectives such as efficiency, cost and environmental impact (see, for example [22] for thermal system design; [23] for CHP plants, [24] for internal gasification combined cycles). Due to their ability for handling non-linear and non-continuous objective functions, evolutionary algorithms have thereby proven to be a robust method for solving such complex programming problems.

In this paper, EMOO based on the evolutionary algorithm [25] is applied to solve the nonlinear master problem with three objectives: the minimization of the annual investment cost (CAPEX), the operating cost including incomes (OPIN), and the overall $\mathrm{CO}_{2}$ emissions of a system (Eq.1). In the evolutionary multi-objective algorithm (EMOO) the continuous variables are not coded as binary genes but are explicitly treated as continuous variables. The algorithm solves the multi-objective optimization by using the dominancy criteria to select the members of the parents population.

$$
\min _{\dot{\mathrm{Q}}_{\mathrm{s}_{\mathrm{i}}}, \mathbf{Y}_{\mathrm{s}_{\mathrm{i}}}}\left[\mathbf{O P I N}, \text { CAPEX, } \quad \mathbf{M}_{\mathbf{C O}_{2}}\right], \quad \text { s.t. }\{\mathbf{E T M}, \mathbf{E I O}, \mathbf{E E}\}
$$

The constraints of the master optimization include the thermo-economic simulation model (ETM) of equipments (sec.2.2), the slave optimization (EIO) and the environomic evaluation (EE). The list of potential equipments is the main input data. Binary variables for the choice of equipments and their maximum available capacity are decision variables. Finally the results of the master optimization (EMOO) are presented by the Pareto optimal frontier. 


\subsection{Thermo-economic simulation models (ETM)}

The thermo-economic models (ETM) compute the performances, the corresponding thermodynamic states (e.g. the temperature level(s) at which heating or cooling is/are delivered) as well as the investment turnkey cost of conversion technologies.

The main input data and parameters include: the maximum available size, the market cost function, the electrical and the thermal efficiencies of technologies.

The simulation results of this step, the list of available energy sources and the energy consumption profiles (including the temperature and power levels) are the main input data for the slave optimization. The flow-sheeting software is mainly used for simulations in this step.

In this paper, six types of district energy conversion technologies have been considered, namely back pressure steam turbines, biomass rankine cycles (BRC), biomass integrated gasification gas engines (BIGGE), biomass integrated gasification gas turbines, production of synthetic natural gas (SNG) and biomass integrated gasification combined cycles (BIGCC) (sec.3).

\subsection{Slave optimization: multi-period energy integration model (EIO)}

Once the state of equipments and their associated heat requirements are determined in ETM step, the usage (utilization) level of each equipment during a yearly operating scheme is optimized by solving a multi-period mixed integer linear programming in the slave optimization.

The input data and parameters used in the slave optimization include the values of the master decision variables, the thermodynamic parameters which are outputs resulting from thermo-economic simulation models, energy consumption profiles and the resources' availability.

The heat cascade, the mass and the energy balance are defined as the main constraints in the slave optimization (MILP). The selection of the objectives is hereby arbitrary as long as the aggregation of terms is robust and consistent with respect to the multiple objectives of the master optimization problem (EMOO).

In the present work, it is proposed to minimize the total operating and emission costs. For all subsystems $s, \forall s=1, \ldots, N_{s}$, that provide $j, \forall j=1, \ldots, N_{j}$, output and consume $i, \forall i=1, \ldots, N_{i}$, input streams through the system boundary, the target can be expressed as a function of their utilization level $f_{s}$ to be optimized, i.e.: 


$$
\begin{gathered}
\min _{\dot{\mathbf{R e}}_{\mathbf{e}, \mathbf{t}}, \dot{\mathbf{R}}_{\mathbf{r}, \mathbf{t}}, \mathbf{Y}_{\mathbf{s}, \mathbf{t}}, \mathbf{f}_{\mathbf{s}, \mathbf{t}}} \sum_{s, t} \mathbf{f}_{s, t}\left(\left[\sum_{i} \dot{Q}_{s_{i}, t}^{+} c_{i, t}^{+}-\sum_{j} \dot{Q}_{s_{j}, t}^{-} c_{j, t}^{-}+\sum_{l}\left(c e l_{l, t}^{+} * \dot{E}_{s, l, t}^{+}-c e l_{l, t}^{-} * \dot{E}_{s, l, t}^{-}\right)\right] * d_{t}\right) \\
+\left[\left(\sum_{s, t} \mathbf{f}_{s, t} * \dot{\mathbf{M}}_{\mathbf{C O}_{\mathbf{2}}, \mathbf{s}, \mathbf{t}} * \operatorname{tax}_{c o_{2}}\right)+c e l_{N_{l}, t}^{+} * \dot{\mathbf{E}}_{\mathbf{g r i d}, \mathbf{t}}^{+}-c e l_{N_{l}, t}^{-} * \dot{\mathbf{E}}_{\text {grid, }, \mathbf{t}}^{-}\right] * d_{t}
\end{gathered}
$$

Where the first therm shows the heating/cooling and the electricity consumption cost minus incomes from selling the heating/cooling and the electricity. The second therm shows the $\mathrm{CO}_{2}$ taxes, and the last therm shows the cost of electricity consumption from the grid minus incomes from the electricity export to the grid.

and subject to:

1. Existence of subsystem $s$ :

$$
f_{\min , s} * \mathbf{y}_{s, t} \leq \mathbf{f}_{s, t} \leq f_{\max , s} * \mathbf{y}_{s, t} \quad \forall s=1, \ldots, N_{s} \quad, \quad \forall t=1, \ldots, T
$$

Where $f_{\min , s}$ and $f_{\text {max }, s}$ are two parameters for showing the minimum and the maximum available capacity of subsystem $s . \mathbf{y}_{\mathbf{s}, \mathbf{t}}$ is the binary variable for existence of subsystem $s$ in time $t$. $\mathbf{f}_{\mathbf{s}, \mathbf{t}}$ is the continuous variable for showing the utilization rate of the subsystem $s$ in time $t$.

2. Heat balance of the temperature interval $r$ and its overall balance:

$$
\sum_{s, i, j} \mathbf{f}_{s, t}\left(\dot{Q}_{s_{j}, r, t}^{-}-\dot{Q}_{s_{i}, r, t}^{+}\right)+\dot{\mathbf{R}}_{r+1, t}-\dot{\mathbf{R}}_{r, t}=0, \quad \dot{R}_{1, t}=0, \dot{R}_{N_{r+1, t}}=0, \forall r, t
$$

Where $\dot{Q}_{s_{i}, t}^{+}$is a parameter for representing the heat consumption in the stream $i$ of subsystem $s$ at time $t$, while $\dot{Q}_{s_{j}, t}^{-}$shows the heat production of the stream $j . \dot{\mathbf{R}}_{\mathbf{r}, \mathbf{t}}^{-}$is a continuous variable for the residual heat from the temperature level $r$ in time $t$. Here, there is a possibility of cascading the residual heat from the higher temperature level $r+1$ to the lower one.

3. $\mathrm{CO}_{2}$ emissions: The $\mathrm{CO}_{2}$ emissions of the net electricity import from the grid and the fuel consumption are considered (overall system emission). If the $\mathrm{CO}_{2}$ emission of the electricity from the grid is higher than the emission from a poly-generation plant, then negative $\mathrm{CO}_{2}$ emission 
will be realized:

$\dot{\mathbf{M}}_{\mathbf{C O}_{\mathbf{2}, \mathbf{s}, \mathbf{t}}}=\sum_{j} \dot{\mathbf{Q}}_{\mathbf{s}_{\mathbf{j}}, \mathbf{t}}^{-} / \eta_{t h, s} * m_{s_{j}, C O_{2}}+\left(\dot{\mathbf{E}}_{\text {grid, } \mathbf{t}}^{+}-\dot{\mathbf{E}}_{\text {grid, } \mathbf{t}}^{-}\right) * m_{g r i d, C O_{2}} \quad \forall s$

Where $m_{s_{j}, C O_{2}}$ is a parameter for the $\mathrm{CO}_{2}$ emissions of consumed fuel in the subsystem $s$ and the stream $j$, while $m_{g r i d, C O_{2}}$ is the $\mathrm{CO}_{2}$ emissions of the electricity from the grid.

4. Electricity balance and electricity cascade: The electricity demand of a consumer in the period $t$ can be supplied with the direct power from each equipment or from the main power grid. Different quality levels are considered for electricity and denoted by $l=1, \ldots, N_{l}$. The highest quality level is $l=N_{l}$ and the lowest is $l=1$. As an assumption, the electricity export and import from the grid has the lowest quality. There is also a possibility of cascading the residual electricity from the higher quality $\left(\dot{R}_{l}^{-}\right)$to the lower quality level.

$$
\sum_{s, l} \mathbf{f}_{s, t}\left(\dot{E}_{s, l, t}^{+}-\dot{E}_{s, l, t}^{-}\right)=\dot{\mathbf{E}}_{g r i d, t}^{+}-\dot{\mathbf{E}}_{g r i d, t}^{-}, \quad \dot{\mathbf{E}}_{g r i d, t}^{+} \geqslant 0, \dot{\mathbf{E}}_{g r i d, t}^{-} \geqslant 0, \forall t
$$

Where $\dot{E}_{s, l, t}^{+}$is a parameter for representing the electricity consumption with the quality level $l$ in the subsystem $s$ and time $t$, while $\dot{E}_{s, l, t}^{-}$shows the electricity production level. $\dot{\mathbf{E}}_{\text {grid, } \mathbf{t}}^{+}$and $\dot{\mathbf{E}}_{\text {grid, } \mathbf{t}}^{-}$are continuous variables for the electricity import and export from the grid in time $t$.

There is also a possibility of cascading the residual electricity from the higher quality $\left(\dot{R}_{l}^{-}\right)$to the lower quality level.

$$
\sum_{s, t} \mathbf{f}_{s, t}\left(\dot{E}_{s, l, t}^{-}-\dot{E}_{s, l, t}^{+}\right)-\sum_{t} \dot{\boldsymbol{R e}}_{l, t}^{-}+\sum_{t} \dot{\boldsymbol{R}}_{N_{l+1}, t}^{-}=0, \quad \forall l
$$

where:

$$
\begin{gathered}
\dot{R} e_{N_{l+1}, t}^{-}=0, \quad \dot{R} e_{1, t}^{-}=\dot{\mathbf{E}}_{g r i d, t}^{-}-\dot{\mathbf{E}}_{g r i d, t}^{+} \\
\mathbf{y} \in\{0,1\}, \quad \dot{\mathbf{R}}_{r} \geq 0, \quad \dot{\mathbf{R e}_{l, t}^{-}} \geq 0
\end{gathered}
$$

The utilization level of demand subsystems are fixed and equal to $1, f_{s}=1$, but the utilization level of equipments as utility subsystems, $\mathbf{f}_{s}$, are variable and optimized. 


\subsection{Assumptions}

The following assumptions and simplifications have been made: The energy system has two main parts, the supply side and the demand side, without considering any networks. The supply side is a central power plant. All conversion technologies are located in this central power plant. There are no restriction for heat exchange between equipments. Physical networks are not simulated in this study. The central plant in the supply side is connected directly to the consumer side without any heat losses or pressure drops. Part load efficiency is not considered and a constant efficiency is defined for each equipments. All costs, as a function of equipments' size, are calibrated from the market data. In the slave optimization the annual investment cost is assumed to be a linear function of equipments' capacity. There are not any limits on resources.

\section{Biomass conversion technologies}

There are several alternative equipments for integrating biomass in the energy system as described in the superstructure of Fig.2. These can be categorized into three groups; conversion equipments like gasifiers, cleaning units and boilers for producing heat and biogas, cogeneration units like engines and gas turbine with gasified biomass fuel, and finally heat recovery and conversion units like steam networks and Rankine Cycles. Subsequently, six alternative configurations extracted from these superstructures are investigated in this paper:

Back pressure steam turbine (BPST): It is the most common technology used in CHP plants. The biomass-fired boiler produces high pressure steam, which is expanded in the back pressure turbine for electricity generation. The low-pressure steam extracted from the turbine is then used in the district heating network (Fig.3). The simulation model for the boiler [26] and the steam turbine [27] proposed by F.Marechal are used in the current work.

Biomass integrated gasification gas engine (BIGGE): In this configuration, biomass is used in the gasification process carried out with oxygen and steam at high temperatures $(800 \mathrm{C})$ in a circulating fluidized bed (CFB) gasifier. The produced gas, after tar cleaning and cooling down, is fired in a gas engine with $43 \%$ thermal and $39 \%$ electrical efficiency for heat and electricity production. There is also the possibility 


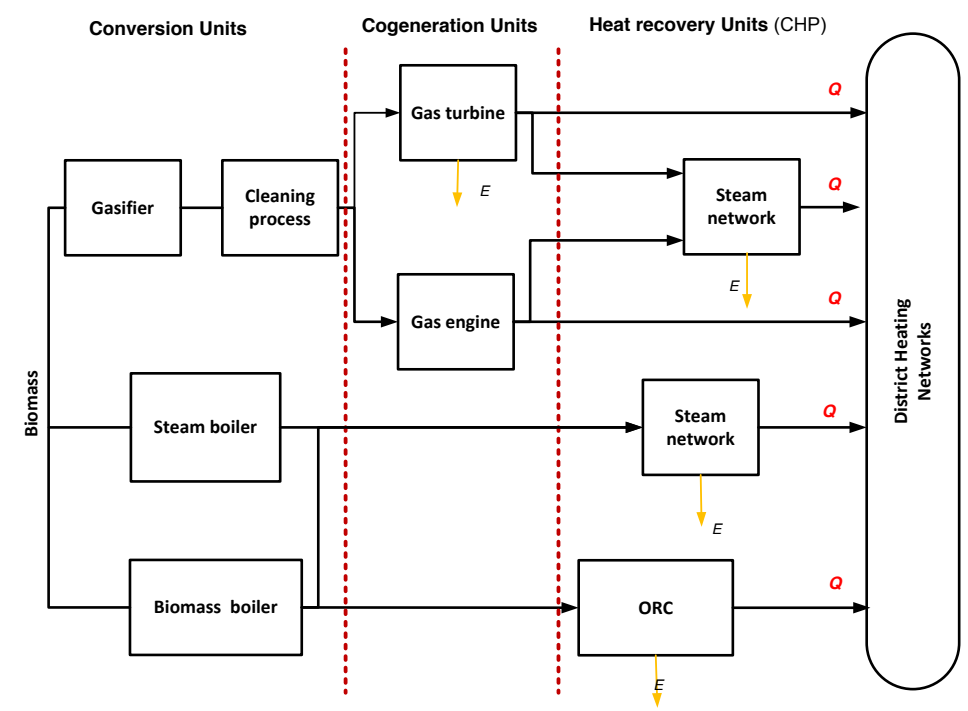

Figure 2: Alternative biomass conversion technologies

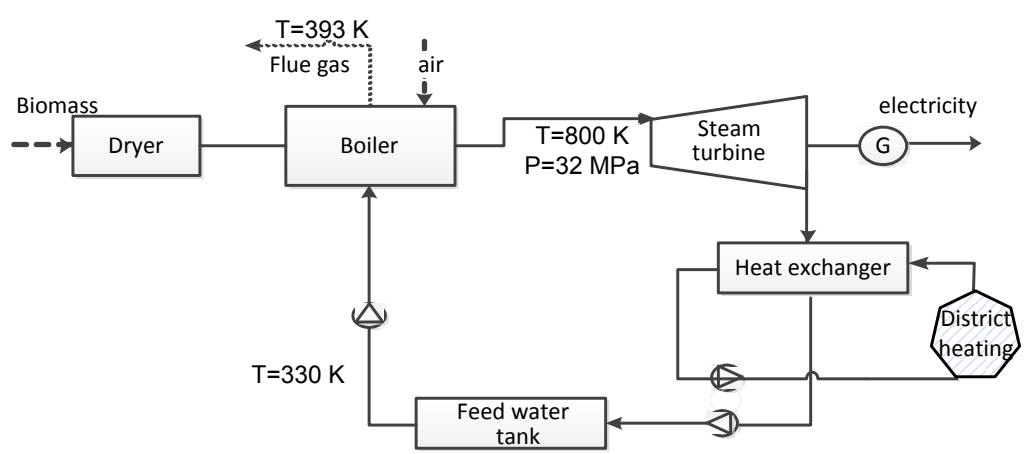

Figure 3: Back pressure steam turbine (BPST)

of integrating a steam turbine after the gas engine. A thermo-economic simulation model of a biomass gasification and gas cleaning process was addressed in [24] and is used for the purpose of this work.

Biomass integrated gasification gas turbine (BIGGT): Here the biogas produced by gasification is first cleaned from tars and particular matters and is then burned in a gas turbine (Fig.4). The heat from 
exhaust gases is used for the district heating [24].

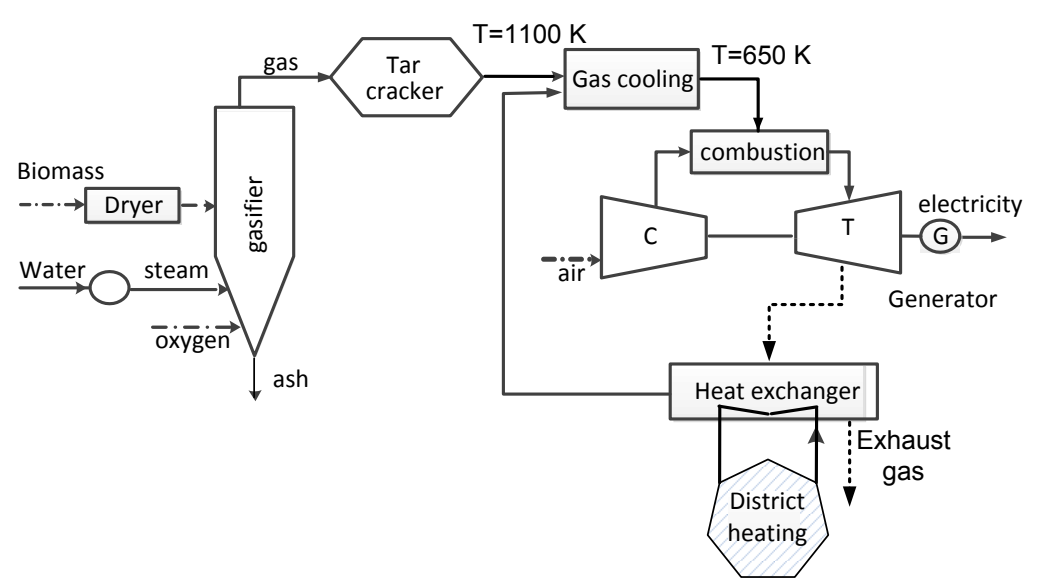

Figure 4: Biomass integrated gasification gas turbine (BIGGT)

Biomass Rankine Cycle (BRC): Biomass is burned in a boiler. The boiler is coupled with an ORC through a closed thermal oil cycle (Fig.5). The working fluid is vaporized by the hot oil and expanded in a turbine for electricity generation. Octamethyltrisiloxane (OMTS) has been chosen as a working fluid. Relevant assumptions with details data are presented in [28].

Biomass integrated gasification combined cycle (BIGCC): This technology is the combination of the gasification with the gas turbine and the steam cycle [27]. Here the biogas from gasification is burned in the gas turbine. Exhaust gases are used in the heat recovery steam cycle. Steam is expanded in the turbine and remaining heat is used in the district heating system.

Production of synthetic natural gas (SNG): hydrothermal gasification of wet biomass is an alternative process to produce synthetic natural gas (SNG). After tar cleaning and cooling down procedures, methane synthesis is used to increase calorific value of the produced gas. Finally the carbon dioxide is removed. The obtained synthetic natural gas can be sold and sent to the gas grid. The heat obtained during SNG production can be used in the district heating networks. A process 


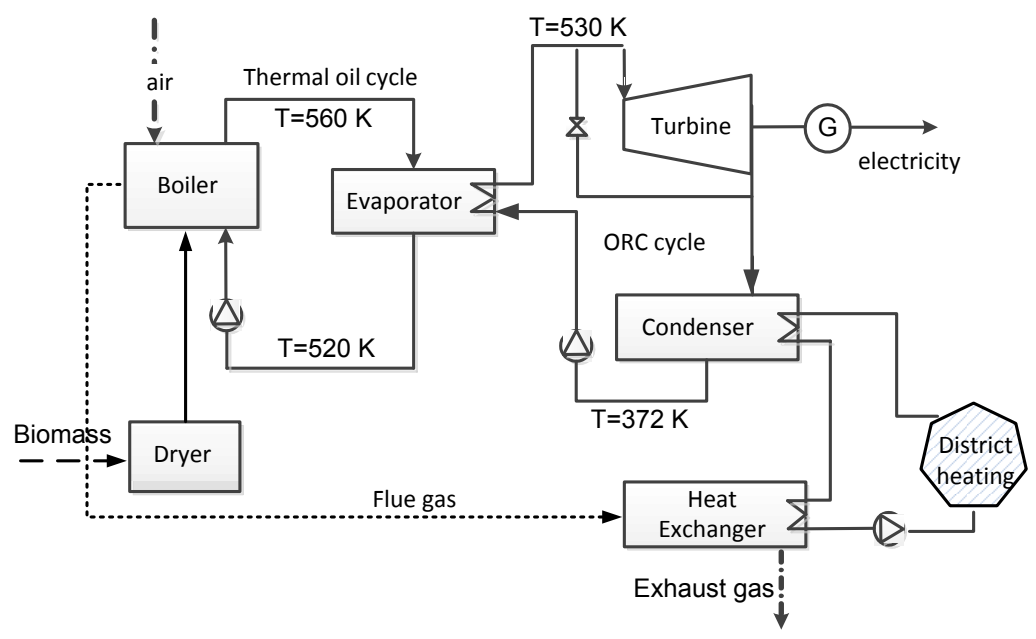

Figure 5: Biomass Rankine Cycle (BRC)

model for the polygeneration of Synthetic Natural Gas (SNG), power and heat by catalytic hydrothermal gasification of biomass and biomass wastes was presented in [29]. In the aforementioned study, a thermodynamic and thermo-economic simulation models for hydrolysis, salt separation, gasification and the separation of $\mathrm{CH} 4, \mathrm{CO} 2, \mathrm{H} 2$ and $\mathrm{H} 2 \mathrm{O}$ at high pressure are developed and validated with experimental data. This simulation model is used in this paper.

Following the second step of the methodology, thermodynamic simulation models are developed for these alternative options by using commercial flowsheeting software, Belsim.

\section{Illustrative example}

An illustrative example is used to show the application of the proposed methodology. The goal is to supply the energy requirement of a district heating system in a city with 500000 inhabitants. The case comprises five alternative configurations, BPST, BRC, BIGGE, BIGCC, SNG and any other possible combination of them for power and heat services. It should indicate that all units are assumed to be able to operate at any time throughout the whole periods with no limit on the availability of resources (Table.3).

The obtained synthetic natural gas can be sold and sent to the gas grid with 
the green SNG price. The $\mathrm{CO}_{2}$ emission of SNG is computed based on the method presented in [30]. The heat obtained and electricity produced during SNG production process can be used in the district heating [29].

Consumers heat demands from the district heating system are given for 12

Table 3: $\mathrm{CO}_{2}$ Intensity and Price of available resources

\begin{tabular}{lcc}
\hline Resources & $\triangle \mathrm{CO}_{2}:$ & Price: $[31]$ \\
& {$[\mathrm{kg} / \mathrm{MJ}]$} & {$[€ / \mathrm{MJ}]:$} \\
\hline Electricity & $0.3071[32]$ & 0.0198 \\
Natural Gas & 0.0641 & 0.0092 \\
Biomass & 0 & 0.0036 \\
SNG & 0 & 0.0099 \\
\hline
\end{tabular}

periods and one extreme condition with corresponding durations, supply and return temperatures (Table.4). This demand profile is valid for a city with 500,000 inhabitants in Eastern Europe where coal is the main sources for the heat and the power production.

The reference size and capacity ranges of equipments are given in Table.5.

Table 4: Twelve periods data set for the heating demand

\begin{tabular}{|c|c|c|c|c|c|c|c|}
\hline & January & February & March & April & May & June & July \\
\hline Duration $[h]$ & 744 & 672 & 744 & 720 & 604 & 424 & 285 \\
\hline$\tilde{T}_{e x t}\left[{ }^{\circ} \mathrm{C}\right]$ & 1.87 & 4.93 & 7.78 & 11.4 & 14.05 & 15.76 & 16.7 \\
\hline$\tilde{T}_{\text {supply }}\left[{ }^{\circ} \mathrm{C}\right]$ & 90 & 85 & 85 & 75 & 70 & 70 & 68 \\
\hline$\tilde{T}_{\text {return }}\left[{ }^{\circ} \mathrm{C}\right]$ & 50 & 50 & 48 & 45 & 45 & 45 & 48 \\
\hline$\tilde{Q}[M W]$ & 350 & 310 & 300 & 200 & 90 & 70 & 60 \\
\hline & August & September & October & November & December & Extreme & \\
\hline Duration $[h]$ & 160 & 492 & 658 & 719 & 744 & 1 & \\
\hline$\tilde{T}_{e x t}\left[{ }^{\circ} \mathrm{C}\right]$ & 16.69 & 15.61 & 12.8 & 10.38 & 5.09 & -8 & \\
\hline$\tilde{T}_{\text {supply }}\left[{ }^{\circ} \mathrm{C}\right]$ & 70 & 70 & 75 & 85 & 90 & 110 & \\
\hline$\tilde{T}_{\text {return }}\left[{ }^{\circ} \mathrm{C}\right]$ & 45 & 45 & 45 & 50 & 50 & 55 & \\
\hline$\tilde{Q}[k W]$ & 62 & 100 & 200 & 300 & 350 & 600 & \\
\hline
\end{tabular}

Economical and technical data of each technology were taken from the literature [15]; [34]; [35]. The investment cost could be estimated with linear or non linear function. In this case study, the annual investment cost is assumed to be a linear function of equipments' capacity, and characterized by 
two parameters, $\beta_{s}[€ / \mathrm{kW} / \mathrm{an}]$ and $\alpha_{s}[€ /$ an] (Table 5).

Any combinations of these five options are allowed with two types of avail-

Table 5: Reference capacity of each equipments with the corresponding ranges

\begin{tabular}{|c|c|c|c|c|c|c|}
\hline Equipment & $\begin{array}{l}\text { Reference: } \\
{\left[M W_{t h / e l}\right]}\end{array}$ & $\begin{array}{l}\text { Ranges: } \\
{\left[M W_{t h / e l}\right]}\end{array}$ & $\begin{array}{c}\beta_{s} \\
{[€ / \mathrm{kW} / \mathrm{an}]}\end{array}$ & $\begin{array}{c}\alpha_{s} \\
{[\mathrm{k} € / \mathrm{an}]}\end{array}$ & $\begin{array}{c}\mathrm{O \& M} \\
{[€ / \mathrm{MWh}]}\end{array}$ & \\
\hline Boiler (NG) & $42_{t h}$ & {$\left[\begin{array}{ll}0 & 210\end{array}\right]$} & 14 & 84 & 3.5 & [20] \\
\hline Boiler (BM) & $42_{t h}$ & {$\left[\begin{array}{ll}0 & 210\end{array}\right]$} & 14 & 84 & 10.4 & [20] \\
\hline Engine (NG) & $5_{e l}$ & {$\left[\begin{array}{ll}0 & 100\end{array}\right]$} & 25 & 15 & 10 & [15] \\
\hline Engine (BM) & $5_{e l}$ & {$\left[\begin{array}{ll}0 & 50\end{array}\right]$} & 25 & 15 & 10 & {$[15]$} \\
\hline $\mathrm{SNG}^{*}$ & $20_{b m}$ & {$\left[\begin{array}{ll}0 & 200\end{array}\right]$} & 67 & $10^{3}$ & 40 & [36] \\
\hline Gasifier* & $20_{b m}$ & {$\left[\begin{array}{ll}0 & 200\end{array}\right]$} & 64 & $10^{3}$ & 1 & {$[36]$} \\
\hline Gas turbine(NG) & $20_{e l}$ & {$\left[\begin{array}{ll}0 & 200\end{array}\right]$} & 73 & 14 & 50 & [15] \\
\hline Gas turbine(BM) & $20_{e l}$ & {$\left[\begin{array}{ll}0 & 200\end{array}\right]$} & 73 & 14 & 50 & {$[15]$} \\
\hline Steam turbine & $30_{e l}$ & {$\left[\begin{array}{ll}0 & 200\end{array}\right]$} & 32 & 272 & 10 & [20] \\
\hline $\mathrm{BRC}$ & $2_{e l}$ & {$\left[\begin{array}{ll}0 & 20\end{array}\right]$} & 38.5 & 96 & 30 & {$[37]$} \\
\hline
\end{tabular}

BM: Biomass, NG: Natural gas

* It is based on the fuel consumption

able resources; biomass and natural gas without any limit on the availability of resources and with the economic and environmental conditions given in Table.3. The properties of wood specified in the illustrative example are given in Table.6. As an assumption, the biomass boiler with $80 \%$ efficiency has 3 times more maintenance cost compare to the natural gas boiler.

Furthermore, power generation is considered as an opportunity for producers.

Regarding the optimization problem, the integer variables are defined in

Table 6: Composition and fuel properties of wood

\begin{tabular}{lllllll}
\hline $\begin{array}{l}\mathrm{C} \\
(\% \text { daf })\end{array}$ & $\begin{array}{l}\mathrm{H} \\
(\% \text { daf })\end{array}$ & $\begin{array}{l}\text { O } \\
(\% \text { daf })\end{array}$ & $\begin{array}{l}\mathrm{N} \\
(\% \text { daf })\end{array}$ & $\begin{array}{l}\text { Moisture } \\
(\% \text { af })\end{array}$ & $\begin{array}{l}\mathrm{HHV} \\
(\mathrm{MJ} / \mathrm{kg})\end{array}$ & $\begin{array}{l}\mathrm{LHV} \\
(\mathrm{MJ} / \mathrm{kg})\end{array}$ \\
\hline 51.09 & 5.75 & 42.97 & 0.19 & 50 & 19.6 & 16.2
\end{tabular}

Notes: \% weight percentages; daf: dry ash free; af: ash free. HHV and LHV are on dry basis but considering for the LHV the requirements for $50 \%$ moisture evaporation.

the master optimization to select the type of equipments, while continuous variables are used for setting the maximum available capacity of selected equipments. The $\mathrm{CO}_{2}$ weighing factor for taxes varies from 0 to $0.5[€ / \mathrm{kg}]$ and is also defined as a continuous variable in the master optimization. The 
fuel choice and the utilization level of selected equipments are left to the slave MILP optimization. If the selected capacity in the master optimization is underestimated, a back up boiler is considered in the slave optimization to cover the remaining heat demand.

\subsection{Results and discussion}

The Pareto curve resulting from 1500 evaluation of the master problem is given on Fig.6. The calculations have been carried out by parallel computing on a high-performance cluster (EPFL Pleiades cluster). This figure shows two main clusters. The first cluster, with the higher operating cost and $\mathrm{CO}_{2}$ emission, features mainly natural gas base technologies. The second cluster features gasifiers, gas turbine, engines, boilers and SNG mainly with biomass resources. In this group the investment cost is higher but $\mathrm{CO}_{2}$ emission and operation cost including incomes are quite low.

Six interesting superstructures among all solutions are selected for detail

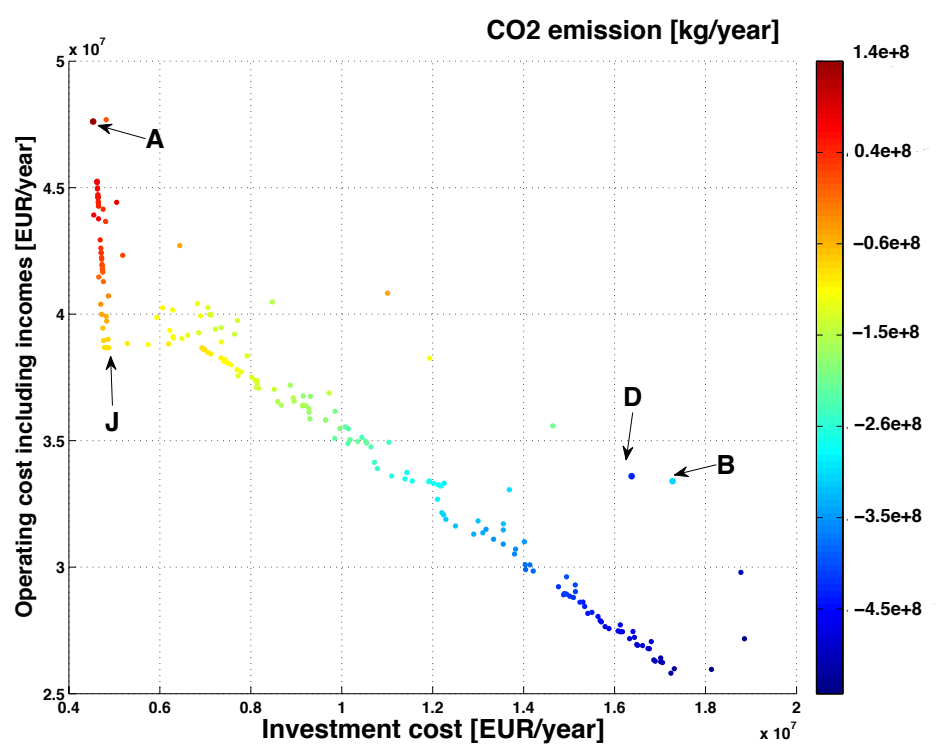

Figure 6: Multi objective optimisation results: EMOO

analysis. Fig.7 shows the mean supplied heat and power, fuel consumption and heat demand of these configurations during 6966 operating hours of a year. 
These configurations are; $\mathbf{A}$ (BPST) features steam networks, a biomass

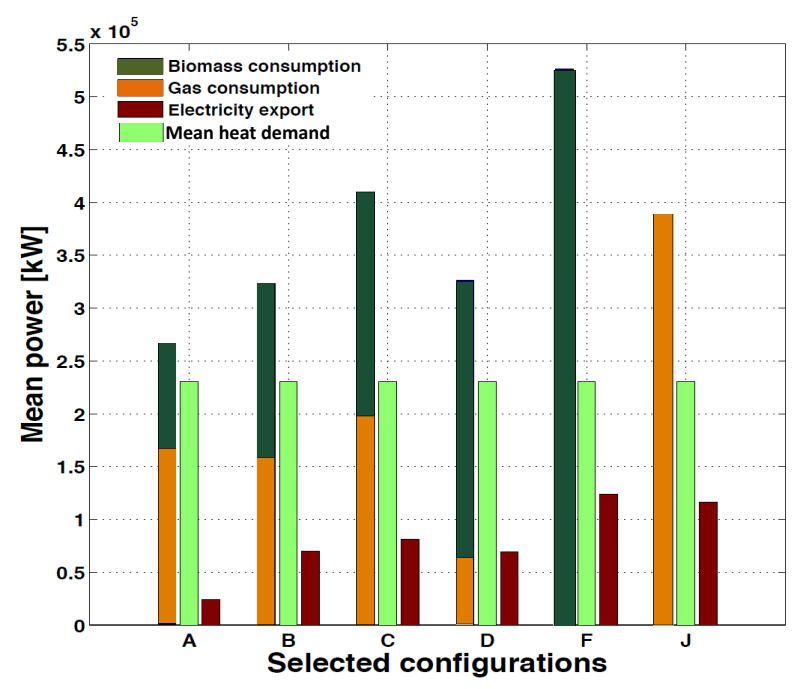

Figure 7: Comparison between 6 selected configurations

Table 7: Environomic indicators corresponding to the selected superstructures

\begin{tabular}{lccccccc}
\hline & OP & OPIN & INV & TOTAL & NetCO & $\mathrm{CO}_{2}$ & GPC \\
& {$\left[10^{6} € /\right.$ an $]$} & {$\left[10^{6} € / \mathrm{an}\right]$} & {$\left[10^{6} € / \mathrm{an}\right]$} & {$\left[10^{6} € / \mathrm{an}\right]$} & {$\left[10^{3} \mathrm{~kg} / \mathrm{MJ}\right]$} & {$\left[10^{3} \mathrm{~kg} / \mathrm{MJ}\right]$} & {$\left[10^{3} € / M J_{\text {th }}\right]$} \\
\hline $\mathrm{A}$ (BPST) & 60 & 48 & 5 & 53 & 10 & 38.6 & 9.2 \\
$\mathrm{~B}$ (BIGGE) & 68 & 33 & 17 & 51 & -39 & 32.2 & 8.9 \\
$\mathrm{C}$ (BIGGT) & 101 & 61 & 24 & 85 & -41 & 38.6 & 14.7 \\
$\mathrm{D}$ (BGICC) & 68 & 34 & 16 & 50 & -57 & 12.8 & 8.6 \\
$\mathrm{~F}$ (Biomass) & 114 & 52 & 39 & 91 & -106 & 0 & 15.8 \\
$\mathrm{~J}$ (Gas) & 73 & 39 & 5 & 43 & -6 & 65 & 7.5 \\
\hline
\end{tabular}

and a natural gas boiler; B (BIGGE) features a natural gas boiler, steam networks, a gasifier and a gas engine with biomass resources. C (BIGGT) features a natural gas boiler, steam networks, a gasifier and a gas turbine with biomass resources. D(BIGCC), has the same configuration like $\mathbf{B}$ but also with a biomass boiler. $\mathbf{F}$ features SNG, a bio gas engine and a gas turbine, steam networks, a gasifier and a boiler with only the biomass fuel, and finally $\mathbf{J}$ features a natural gas boiler, steam networks and a natural gas engine. In this configuration the only available resources is the natural gas. 


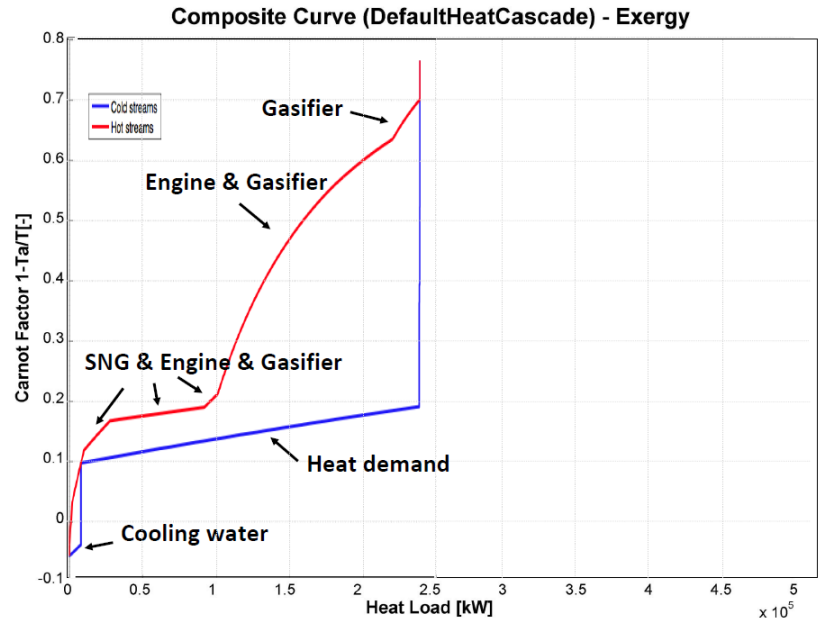

Figure 8: Carnot composite curve of the configuration G

Three objectives, annual investment (INV) and operating (OPIN) cost

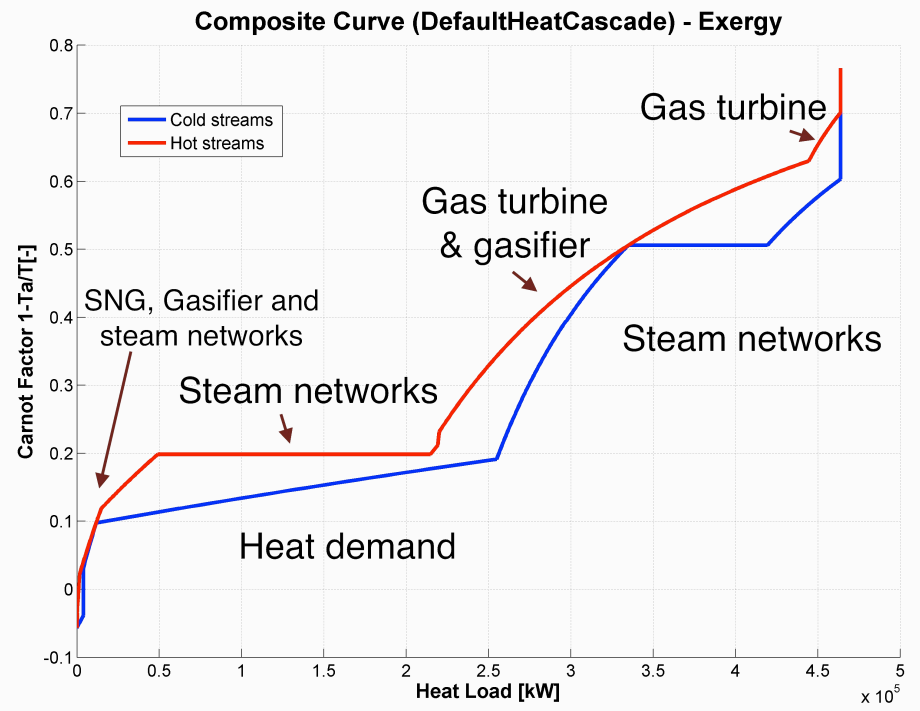

Figure 9: Carnot composite curve of the configuration $\mathrm{H}$ 


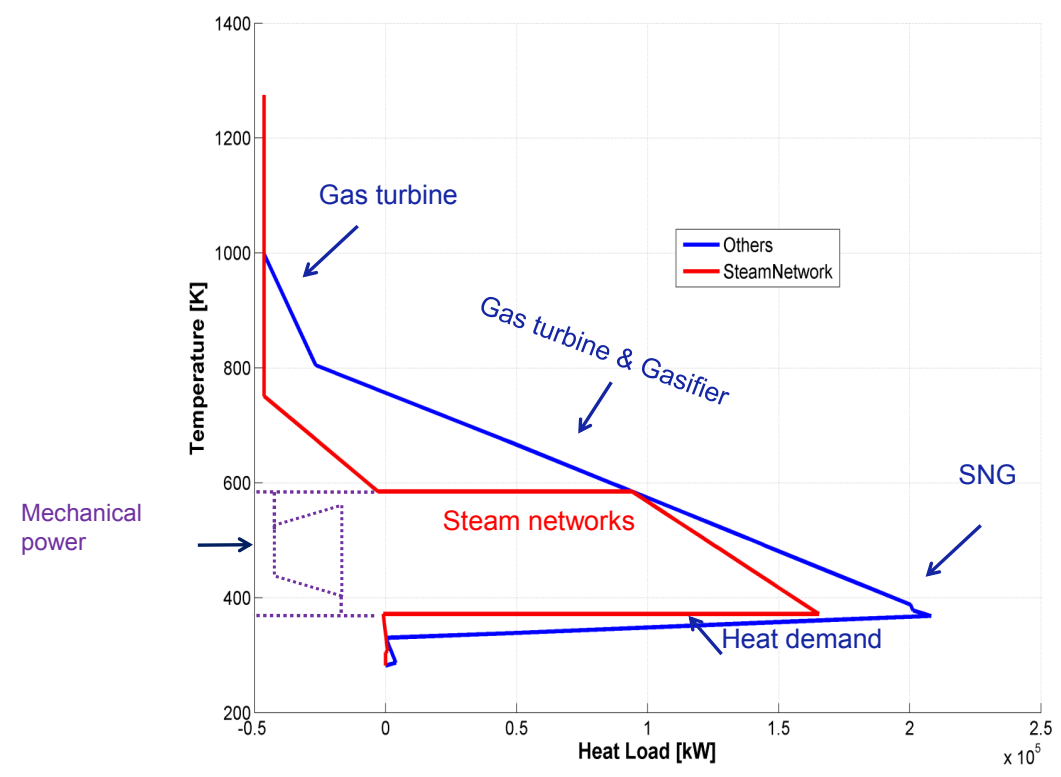

Figure 10: Grand composite curve of the configuration $\mathrm{H}$

and $\mathrm{CO}_{2}$ (NetCO2) emission, of these six configurations are summarized in Table 7. Due to the high emission of electricity from the grid, the negative overall $\mathrm{CO}_{2}$ emission is realized (Eq.5). The total annual cost divided by annual supplied heat, GPC, is also considered as an indicator to evaluate the economic profitability of each configuration.

Configuration $\mathbf{J}$ fueled only by natural gas, while configuration $\mathbf{F}$ consumes mainly biomass fuel. $\mathbf{F}$ shows higher primary energy savings and $\mathrm{CO}_{2}$ emission reduction through the gradual increase of biomass sources.

However, GPC of configuration, $\mathbf{J}$ is $52 \%$ less than $\mathbf{F}$, which means higher economic profitability is achieved with natural gas-based technologies compare to the biomass usage. Due to the high operation and investment cost, configurations $\mathbf{C}$ and $\mathbf{F}$ are not part of the Pareto frontier.

\subsubsection{Exergy losses}

Two configurations; $\mathbf{H}$ with gasifiers, gas turbines, SNG and steam networks, and $\mathbf{G}$ with gasifiers, engines and SNG but with out steam networks, are selected to analyse the exergy losses [38].

Fig.9 and 8 show the carnot composite curve [39] of configurations $H$ and 
G. On the plots, the hot composite curve [39] represents the heat provided by the poly-generation plant. The cold composite curve mainly shows the consumers heat requirement. The cooling water is also considered for cooling down the system.

There are exergy losses in configuration $B$, while in configuration $E$, exergy losses are $80 \%$ decreased by integrating the steam networks.

\section{Conclusion:}

A method for the preliminary design of integrated urban energy systems has been presented in this paper. A systematic procedure including process design and energy integration techniques with simultaneous consideration of multi-periods and multi-objective aspects, economic and environment targets, for energy system design is proposed. It combines the use of optimization techniques with a data base of thermo economic models that are used to build conversion technologies superstructures.

Considering all these concepts in a single optimization model makes it difficult to solve. In this study, a decomposition approach is used to deal with this complexity. In order to do so, a multi-objective optimization model using evolutionary algorithms (MOO) and MILP model has been developed. The developed model is mainly used for the preliminary conceptual design and sizing optimization, where the system configuration is optimized based on the economic and environmental targets. The model is used to study the large scale integration of renewable energy like biomass in district heating systems.

The results will be used to propose energy conversion systems configurations that will have to be optimized in more detail before envisaging the optimal operation strategies.

The illustrative example demonstrates the ability of the developed method to solve a real scale problem. In the example, the energy system is required to meet the heat demands of an urban area while considering both economic and environmental objectives. Furthermore, power generation is considered as an opportunity for the utility company.

From the results it appears that natural gas is less attractive than biomass when $\mathrm{CO}_{2}$ taxes are included, but it is sensitive to the $\mathrm{CO}_{2}$ taxes and the resources price. However, higher economic profitability (up to 52\%) is yet achieved with natural gas-based technologies. Furthermore, higher primary energy savings and $\mathrm{CO}_{2}$ emission reduction (up to 40\%) are obtained through 
the gradual increase of biomass usage.

The comparison between the carnot composite curves of configurations shows the advantages of using steam networks for decreasing exergy losses and $\mathrm{CO}_{2}$ emission due to the high $\mathrm{CO}_{2}$ emission of the grid electricity. However, BRC loses its interest when steam networks are integrated. The boiler has little competitive advantage as the gas turbine and gasifier combination can provide heat and electricity with lower $\mathrm{CO}_{2}$ emission.

In conclusion, the developed model is able to study the effects of polygeneration technologies on environmental and economic targets by a decomposition approach.

In the future study, district networks, thermal panels and photovoltaics (PV), as well as storage systems should be integrated in the optimization model.

\section{Nomenclature}

MILP mixed integer linear programming

MOO multi objective optimisation

EIO energy integration optimisation

ETM thermodynamic model of energy conversion technologies

EE environomic evaluation

$O P \quad$ annual operation expences, $€$

$I N V$ annual investment cost, $€$

$O P I N$ annual operation cost including incomes, $€$

$\mathrm{CO}_{2}$ annual $\mathrm{CO}_{2}$ emission in a plant per kWh supplied heat and power, $\mathrm{kg} / \mathrm{kWh}$

$\mathrm{NetCO}_{2}$ annual overall $\mathrm{CO}_{2}$ emission in the system per $\mathrm{kWh}$ supplied heat and power, $\mathrm{kg} / \mathrm{kWh}$

$G P C$ Gross production cost, $€ / k W h_{t h}$

$\mathbf{f}_{\mathbf{s}, \mathbf{t}} \quad$ utilization rate of subsystem $s$, in time $t$

$f_{m i n}$ minimum available capacity of subsystem $s, \mathrm{~kW}$

$f_{\max }$ maximum available capacity of subsystem $s, \mathrm{~kW}$

$\dot{Q}_{s_{i}, t}^{+} \quad$ heat consumption of subsystem $s_{i}$ in time $t, \mathrm{~kW}$

$\dot{Q}_{s_{j}, t}^{-} \quad$ heat production of subsystem $s_{j}$ in time $t, \mathrm{~kW}$ 
$\dot{E}_{s, l, t}^{+} \quad$ electricity consumption with quality level $l$, in subsystem $s$ in time $t, \mathrm{~kW}$

$\dot{E}_{s, l, t}^{-} \quad$ electricity supply with quality level $l$, in subsystem $s$ in time $t, \mathrm{~kW}$

$\dot{\mathrm{E}}_{\text {grid,t }}^{+}$electricity import from the grid, in time $t, \mathrm{~kW}$

$\dot{\mathbf{E}}_{\text {grid,t }}^{-}$electricity export from the grid, in time $t, \mathrm{~kW}$

$\dot{\mathbf{R}}_{\mathbf{r}, \mathbf{t}}^{-} \quad$ residual heat from temperature level $r$, in time $t$

$\dot{\mathbf{R}} \mathbf{e}_{\mathbf{r}, \mathbf{t}}^{-} \quad$ residual electricity from the quality level $l$, in time $t$

$m_{s_{j}, \mathrm{CO}_{2}} \mathrm{CO}_{2}$ emission of the fuel consumed in the subsystem $s$ and stream $j, \mathrm{~kg} \mathrm{CO}_{2} / \mathrm{kWh}$

$m_{\text {grid, } \mathrm{CO}_{2}} \mathrm{CO}_{2}$ emission of electricity from grid, $\mathrm{kg} \mathrm{CO}_{2} / \mathrm{kWh}$

$\mathbf{M}_{\mathbf{C O}_{2}, \mathrm{~s}} C_{2}$ emission produced by subsystem $s$

$\dot{C}_{i, t}^{+} \quad$ heat consumption cost of subsystem $s_{i}$ in time $t, € / \mathrm{kWh}$

$\dot{C}_{j, t}^{-} \quad$ heat production benefit of subsystem $s_{j}$ in time $t, € / \mathrm{kWh}$

$\mathrm{cel}_{l, t}^{-} \quad$ electricity export benefit of quality $l$, in time $t, € / \mathrm{kWh}$

$\mathrm{cel}_{l, t}^{+} \quad$ electricity import cost of quality $l$, in time $t, € / \mathrm{kWh}$

$\mathbf{y}_{\mathbf{s}, \mathbf{t}} \quad$ binary variables for existence of subsystem $s$ in time $t$

tax $_{\mathrm{CO}_{2}} \mathrm{CO}_{2}$ taxes, $€ / \mathrm{kg} \mathrm{CO}_{2}$

$d_{t} \quad$ duration of period $t, \mathrm{~h}$

$\eta_{t h, s_{i}} \quad$ thermal efficiency of subsystem $s_{i}$

$\tilde{T}_{\text {ext }} \quad$ Out door temperature, ${ }^{\circ} \mathrm{C}$

$\tilde{T}_{\text {supply }}$ Hot water supply temperature to DHN, ${ }^{\circ} \mathrm{C}$

$\tilde{T}_{\text {return }}$ Hot water return temperature from DHN, ${ }^{\circ} \mathrm{C}$

DHN District Heating Networks

$O \& M$ Operation and maintenance cost, $€ / M W h$

$\alpha_{s}, \beta_{s} \quad$ investment linear function's parameters 


\section{References}

[1] R. Frischknecht, N. Jungbluth, H.-J. Althaus, G. Doka, R. Dones, T. Heck, S. Hellweg, R. Hischier, T. Nemecek, G. Rebitzer, M. Spielmann, The ecoinvent database: Overview and methodological framework, The International Journal of Life Cycle Assessment 10 (2005) 3 -9 .

[2] L. Tock, M. Gassner, F. Marchal, Thermochemical production of liquid fuels from biomass: Thermo-economic modeling, process design and process integration analysis, Biomass and Bioenergy 34 (2010) 1838 1854.

[3] H. Li, H. Hong, H. Jin, R. Cai, Analysis of a feasible polygeneration system for power and methanol production taking natural gas and biomass as materials, Applied Energy 87 (2010) 2846 - 2853.

[4] D. Connolly, H. Lund, B. Mathiesen, M. Leahy, A review of computer tools for analysing the integration of renewable energy into various energy systems, Applied Energy 87 (2010) 1059 - 1082.

[5] J. A. Parise, L. C. C. Martinez, R. P. Marques, J. B. Mena, J. V. Vargas, A study of the thermodynamic performance and $\mathrm{Co}_{2}$ emissions of a vapour compression bio-trigeneration system, Applied Thermal Engineering 31 (2011) 1411 - 1420.

[6] F. A. Al-Sulaiman, F. Hamdullahpur, I. Dincer, Greenhouse gas emission and exergy assessments of an integrated organic rankine cycle with a biomass combustor for combined cooling, heating and power production, Applied Thermal Engineering 31 (2011) 439 - 446.

[7] M. Pavlas, P. Stehlik, J. Oral, J. Klemes, J.-K. Kim, B. Firth, Heat integrated heat pumping for biomass gasification processing, Applied Thermal Engineering 30 (2010) 30 - 35 .

[8] N. T. Raj, S. Iniyan, R. Goic, A review of renewable energy based cogeneration technologies, Renewable and Sustainable Energy Reviews 15 (2011) $3640-3648$.

[9] S. A. Papoulias, I. E. Grossmann, A structural optimization approach in process synthesis-i : Utility systems, Computers \& Chemical Engineering 7 (1983) $695-706$. 
[10] R. Iyer, I. Grossmann, Synthesis and operational planning of utility systems for multiperiod operation, Computers \& Chemical Engineering 22 (1998) $979-993$.

[11] J. Sderman, P. Ahtila, Optimisation model for integration of cooling and heating systems in large industrial plants, Applied Thermal Engineering 30 (2010) $15-22$.

[12] K. Kavvadias, A. Tosios, Z. Maroulis, Design of a combined heating, cooling and power system: Sizing, operation strategy selection and parametric analysis, Energy Conversion and Management 51 (2010) 833 845 .

[13] E. Cardona, A. Piacentino, A methodology for sizing a trigeneration plant in mediterranean areas, Applied Thermal Engineering 23 (2003) $1665-1680$.

[14] A. Piacentino, F. Cardona, An original multi-objective criterion for the design of small-scale polygeneration systems based on realistic operating conditions, Applied Thermal Engineering 28 (2008) 2391 - 2404.

[15] C. Rubio-Maya, J. Uche-Marcuello, A. Martnez-Gracia, A. A. BayodRjula, Design optimization of a polygeneration plant fuelled by natural gas and renewable energy sources, Applied Energy 88 (2011) 449 - 457.

[16] G. G. Dimopoulos, C. A. Frangopoulos, Optimization of energy systems based on evolutionary and social metaphors, Energy 33 (2008) 171 179 .

[17] C. Weber, N. Shah, Optimisation based design of a district energy system for an eco-town in the united kingdom, Energy 36 (2011) 1292 -1308 .

[18] A. A. Bazmi, G. Zahedi, Sustainable energy systems: Role of optimization modeling techniques in power generation and supply-a review, Renewable and Sustainable Energy Reviews 15 (2011) 3480 - 3500.

[19] C. Weber, F. Marchal, D. Favrat, S. Kraines, Optimization of an sofcbased decentralized polygeneration system for providing energy services in an office-building in tokyo, Applied Thermal Engineering 26 (2006) $1409-1419$. 
[20] C. Weber, Multi-objective design and optimization of district energy systems including polygeneration energy conversion technologies, Ph.D. thesis, Ecole Polytechnique Federale de Lausanne, Switzerland, 2008.

[21] R. Bolliger, Methodologie de la synthese des systemes energetiques industriels, Ph.D. thesis, Ecole Polytechnique Federale de Lausanne, Switzerland, 2010.

[22] A. Lazzaretto, A. Toffolo, Energy, economy and environment as objectives in multi-criterion optimization of thermal systems design, Energy 29 (2004) 1139 - 1157.

[23] H. Li, F. Marchal, M. Burer, D. Favrat, Multi-objective optimization of an advanced combined cycle power plant including $\mathrm{CO}_{2}$ separation options, Energy 31 (2006) 3117 - 3134.

[24] D. Brown, M. Gassner, T. Fuchino, F. Marchal, Thermo-economic analysis for the optimal conceptual design of biomass gasification energy conversion systems, Applied Thermal Engineering 29 (2009) 2137 2152.

[25] G. Leyland, Multi-objective optimization applied to industrial energy problems, Ph.D. thesis, Ecole Polytechnique Federale de Lausanne, Switzerland, 2002.

[26] F. Marechal, B. Kalitventzeff, Process integration: Selection of the optimal utility system, Computers and Chemical Engineering 22, Supplement 1 (1998) S149 - S156.

[27] F. Marechal, B. Kalitventzeff, Identification of the optimal pressure levels in steam networks using integrated combined heat and power method, Chemical Engineering Science 52 (1997) 2977 - 2989.

[28] U. Drescher, D. Bruggemann, Fluid selection for the organic rankine cycle (orc) in biomass power and heat plants, Applied Thermal Engineering 27 (2007) $223-228$.

[29] M. Gassner, R. Baciocchi, F. Marchal, M. Mazzotti, Integrated design of a gas separation system for the upgrade of crude sng with membranes, Chemical Engineering and Processing: Process Intensification 48 (2009) $1391-1404$. 
[30] L. Gerber, M. Gassner, F. Marechal, Systematic integration of lca in process systems design: Application to combined fuel and electricity production from lignocellulosic biomass, Computers and Chemical Engineering 35 (2011) $1265-1280$.

[31] IEA, Energy statistics 2011, relation with member countries poland, international energy agency (2011). Viewed 13 January.

[32] IPCC, Intergovernmental panel on climate change, IPCC Fourth Assessment Report, The Physical Science Basis, Geneva, CH, Switzerland (2007).

[33] L. Girardin, F. Marechal, M. Dubuis, N. Calame-Darbellay, D. Favrat, Energis: A geographical information based system for the evaluation of integrated energy conversion systems in urban areas, Energy 35 (2010) $830-840$.

[34] H. Onovwiona, V. Ugursal, Residential cogeneration systems: review of the current technology, Renewable and Sustainable Energy Reviews 10 (2006) $389-431$.

[35] D. Wu, R. Wang, Combined cooling, heating and power: A review, Progress in Energy and Combustion Science 32 (2006) 459 - 495.

[36] M. Gassner, F. Marchal, Thermo-economic process model for thermochemical production of synthetic natural gas (sng) from lignocellulosic biomass, Biomass and Bioenergy 33 (2009) 1587 - 1604.

[37] T. Guo, H. Wang, S. Zhang, Fluids and parameters optimization for a novel cogeneration system driven by low-temperature geothermal sources, Energy 36 (2011) 2639 - 2649.

[38] D. Favrat, F. Marechal, O. Epelly, The challenge of introducing an exergy indicator in a local law on energy, Energy 33 (2008) 130 - 136.

[39] F. Marechal, B. Kalitventzeff, Energy integration of industrial sites: tools, methodology and application, Applied Thermal Engineering 18 (1998) $921-933$.

Acknowledgments: The authors would like to acknowledge Veolia Environnement Recherche et Innovation (VERI) for the financial support. 